\title{
The Social and Economic Correlates of Tobacco Consumption in Developing Countries Compared to Developed Countries: Evidence from Burkina Faso and Canada
}

\author{
Ernest Ouedraogo ${ }^{1}$, Yienouyaba Gaetan Ouoba ${ }^{2} \&$ Emmanuel Lompo ${ }^{3}$ \\ ${ }^{1}$ Department of Economics and Management, Université Ouaga 2, Burkina Faso \\ ${ }^{2}$ Department of Economics, Laval University, Canada \\ ${ }^{3}$ Department of Political Science, Laval University, Canada \\ Correspondence: Ernest Ouedraogo, Department of Economics and Management, Université Ouaga 2, Burkina \\ Faso. E-mail: ernestouedra@yahoo.fr
}

Received: June 13, 2020 Accepted: August 17, 2020 Online Published: September 8, 2020

doi:10.5539/gjhs.v12n11p33 URL: https://doi.org/10.5539/gjhs.v12n11p33

\begin{abstract}
This paper examines the socio-demographic and economic determinants of tobacco consumption in a developing country like Burkina Faso compared to a developed country like Canada. Using nationally representative data from the 2016 round of Burkina Faso's Demographic and Health Survey (DHS) and the Canadian Community Health Survey (CCHS) 2015-2016, we estimated multivariate fixed effects models to identify the individual factors associated with tobacco consumption in these countries. We find evidence that age has an inverted U-shaped positive effect on cigarettes consumption in both countries with a peak at 24-35 years old in Burkina Faso and a peak at 40-54 years old in Canada. Second, being single increases the consumption of cigarettes while education and employment reduce cigarettes consumption in both countries. The gender gap in tobacco consumption between men and women is larger in Burkina Faso (5.021 cigarettes) compared to Canada (1.45 cigarettes). Third, while income have a negative impact on cigarettes consumption in Canada, it displays a U-shape effect in Burkina Faso. In light of our findings, tobacco control strategies should therefore consider the social and economic context carefully to effectively address the problem of tobacco use in both developed and developing countries.
\end{abstract}

Keywords: tobacco consumption, Burkina Faso, Canada, economic correlates, social correlates

\section{Introduction}

Tobacco smoking is the leading preventable cause of premature death in both developing and developed countries (WHO, 2015; Reitsma, et al., 2017; Jetty et al., 2017; Bonnechère et al, 2019). Deadly diseases associated with tobacco abuse include lung cancer, pneumonia, vascular diseases, age-related muscle degeneration, respiratory heart disease, chronic obstructive lung disease, stroke, aortic aneurysm and ischaemic heart disease (McGinnis \& Foege, 1993; Wald \& Hackshaw, 1996; Ockene \& Miller, 1997; Jetty et al., 2017). In addition, non-fatal diseases, such as peripheral vascular disease, cataracts, hip fracture, and periodontal disease, caused by smoking can also cause major disability, cost, and inconvenience one's life quality (Wald \& Hackshaw, 1996). Smoking while pregnant also increases the risk of limb reduction defects, spontaneous abortion, ectopic pregnancy, and low birth weight (Wald \& Hackshaw, 1996; Jetty et al., 2017).

Despite these harmful consequences, the phenomenon of smoking continues to raise in developed and developing countries and the situation is even worse in developing countries. In fact, evidence show that the health burden of smoking is disproportionately high in the developing world (Action on Smoking and Health, 2019). According to Action on Smoking and Health, (2019), it is estimated that tens of millions of people in the developing countries would have died from tobacco consumption by 2030. A large majority of child deaths from second-hand smoke occur in Africa and South-East Asian. In addition, smoking in the developing world has been shown to reinforce poverty as already deprived smokers spend less on healthcare, children's education, food, and clothes (Action on Smoking and Health, 2019). In economically developed countries, the impact of smoking on health is also large. According to Wald and Hackshaw (1996), about 3 million people die each year from smoking in economically developed countries, half of them before the age of 70 . 
In Burkina Faso, more than 4800 people are killed by tobacco-caused disease every year (WHO, 2015). More than 12000 children (10-14 years old) and 1645000 adults (15+ years old) continue to use tobacco (WHO, 2015). According to WHO (2017), health care expenditure related to tobacco use represents between 6.0 percent and 15.0 percent of total annual health care costs in the high-income countries like Canada. Studies suggest that smokers can lose about nine years of their life expectancy, and each year, the loss of productivity of citizens who smoke costs Canada \$2.91 billion (WHO, 2017). In Canada, health data by WHO (2017) have shown that, nearly 17.0 percent of deaths in 2014 were attributable to smoking (20 percent among men and 12 percent among women). It therefore appears that the problem of cigarette consumption is a major economic issue. An effective policy to prevent these diseases requires a thorough understanding of tobacco use and associated factors.

Yet, the social context and the level of income between developing and developed countries can lead to some differences in the factors affecting smoking practices in these countries. Evidence of these differences based on country income level was documented by Hosseinpoor et al. (2011). In fact, Hosseinpoor et al. (2011) show that age and wealth have different effects on smoking depending on the country's income level. They also show that while women in the low-income country group were twice as likely to smoke if they were in the lowest wealth quintile compared with the highest, the association was absent in the middle-income country group. In contrast, their results suggest that factors like education have a negative effect on smoking, regardless of if the individuals lived in a low or a middle-income country.

In order to contribute to the literature, this paper aims to investigate the determinants of smoking using data from a developing country (Burkina Faso) and a developed country (Canada). Indeed, the majority of studies on smoking incentives - as measured by cigarette consumption - have focused only on the most at-risk populations of adolescents and youth (Brown \& Rinelli, 2010; Reisi et al., 2014; Mohammadi et al., 2017) and have not included other segments of the population such as adults and seniors. To fill this gap, this study is therefore intended to be more comprehensive in its efforts to understand the overall dynamics of smoking for the general population in Burkina Faso and Canada and the factors that affect cigarette consumption. Our empirical methodology uses multivariate models with fixed effects to estimate the impact of social and economic factors on tobacco consumption using microlevel data from the Canadian Community Health Survey (CCHS) 2015-2016 and Burkina Faso's 2016 Demographic and Health Survey.

We find three major results that contribute to document the factors affecting smoking practices. First, the results suggest that age has an inverted U-shaped positive effect on cigarette consumption in both countries with a peak at 24-35 years old in Burkina Faso and a peak at 40-54 years old in Canada. Second, being a man and being single increases the consumption of cigarette while education and employment reduce cigarettes consumption in both countries. We also find evidence that gender gap in tobacco consumption between men and women is larger in Burkina Faso (5.021 cigarettes) compared to Canada (1.45 cigarettes). Third, while income have a negative impact on cigarettes consumption in Canada, it displays a U-shape effect in Burkina Faso. These results are in line with the work of other authors who have shown that, faced with a lack of employment, lack of education, poverty and family instability, individuals often find refuge in smoking, alcohol and drugs (Pierce et al., 1989; Gritz et al., 1996; Giskes et al., 2005; Huisman et al., 2005; Cho et al., 2008; Kelishadi et al., 2010; Pampel et al., 2015; Goffette, 2016).

The rest of this paper is organized as follows: Section 2 presents the data and descriptive statistics. Section 2 presents the data used in this study and the descriptive statistics. Section 3 presents the econometric model. Section 4 presents the empirical results. Section 6 discusses and concludes the paper.

\section{Data and Descriptive Statistics}

\subsection{Data}

We use data from the 2016 round of Burkina Faso Demographic and Health Survey and the 2015-2016 Canadian Community Health Survey (CCHS). Both surveys collected information on individuals' socio-economic characteristics and health behaviour. The datasets contain individual's information, including the number of cigarettes consumed per day, gender, age, marital status, respondent's income, employment, respondent's level of education, respondent's household income, the number of children under twelve (12) years of age in the respondent's household, and the respondent's geographic location.

\subsection{Descriptive Statistics}

Descriptive statistics for our sample are presented in Table (1) for Canada and Table (2) for Burkina Faso.

In Canada, the data show that an individual consumes an average of 2.73 cigarettes per day. The number of cigarettes varies between 0 and 99 with a variance of 6.78 . This indicates a high variability in the incidence of 
cigarette consumption among individuals. Moreover, our sample is mostly made up of individuals between 25 and 55, who make up half of the sample. There are also 53.11 percent women and 46.89 percent men. We also note that 71.4 percent of individuals reported having a stable job for at least one year, while 28.6 percent reported not having a stable job. Finally, 20.7 percent of individuals reported the presence of a child under the age of 12 in the household. There was also a strong regional disparity in the sample distribution, with a greater majority of respondents coming from Ontario and Quebec while less than 2 percent came from the Yukon, Nanuvut, North West Territories combined. This distribution is also consistent with the population density in Canada. In addition, about one-quarter of the individuals had an employment income of less than $\$ 20,000$ per year.

Table 1. Descriptive statistics (Canada)

\begin{tabular}{|c|c|c|c|c|}
\hline Variable & Moyenne & Std dev. & Min & Max \\
\hline Number of cigarettes per day & 2,728 & 6.785 & 0 & 99 \\
\hline \multicolumn{5}{|l|}{ Age } \\
\hline $12-24$ & 0.079 & 0.271 & 0 & 1 \\
\hline $25-39$ & 0.249 & 0.432 & 0 & 1 \\
\hline $40-54$ & 0.261 & 0.439 & 0 & 1 \\
\hline $55-65$ & 0.215 & 0.411 & 0 & 1 \\
\hline 64 and + & 0.193 & 0.395 & 0 & 1 \\
\hline \multicolumn{5}{|l|}{ Sex } \\
\hline Male & 0.468 & 0.499 & 0 & 1 \\
\hline Female & 0.531 & 0.499 & 0 & 1 \\
\hline \multicolumn{5}{|l|}{ Marital status } \\
\hline Married & 0.447 & 0.497 & 0 & 1 \\
\hline Common law union & 0.118 & 0.323 & 0 & 1 \\
\hline Widowed, divorced, separated & 0.179 & 0.383 & 0 & 1 \\
\hline Single & 0.254 & 0.435 & 0 & 1 \\
\hline \multicolumn{5}{|l|}{ Edution level } \\
\hline Less than secondary & 0.128 & 0.334 & 0 & 1 \\
\hline Secondary & 0.234 & 0.423 & 0 & 1 \\
\hline Higher & 0.636 & 0.481 & 0 & 1 \\
\hline \multicolumn{5}{|l|}{ Work status } \\
\hline Have a stable employment & 0.714 & 0.451 & 0 & 1 \\
\hline No stable employment & 0.285 & 0.451 & 0 & 1 \\
\hline \multicolumn{5}{|c|}{ Children under 12 in the household } \\
\hline Have at least one child under 12 & 0.792 & 0.405 & 0 & 1 \\
\hline No Child Under 12 & 0.207 & 0.405 & 0 & 1 \\
\hline \multicolumn{5}{|l|}{ Region } \\
\hline Newfoundland and Labrador & 0.029 & 0.170 & 0 & 1 \\
\hline Prince Edouard Island & 0.016 & 0.126 & 0 & 1 \\
\hline Nova Scotia & 0.043 & 0.203 & 0 & 1 \\
\hline New Brunswick & 0.029 & 0.170 & 0 & 1 \\
\hline Quebec & 0.217 & 0.412 & 0 & 1 \\
\hline Ontario & 0.290 & 0.453 & 0 & 1 \\
\hline Manitoba & 0.049 & 0.217 & 0 & 1 \\
\hline Saskatchewan & 0.041 & 0.200 & 0 & 1 \\
\hline Alberta & 0.125 & 0.331 & 0 & 1 \\
\hline
\end{tabular}




\begin{tabular}{lllll}
\hline British Columbia & 0.130 & 0.336 & 0 & 1 \\
Yukon & 0.008 & 0.092 & 0 & 1 \\
NorthWest Territories & 0.009 & 0.094 & 0 & 1 \\
Nunavut & 0.008 & 0.090 & 0 & 1 \\
\hline Household total annual income & & & & \\
Less than 20000 & 0.098 & 0.297 & 0 & 1 \\
20000-39999 & 0.162 & 0.369 & 0 & 1 \\
$40000-59999$ & 0.161 & 0.367 & 0 & 1 \\
$60000-79999$ & 0.140 & 0.347 & 0 & 1 \\
80000 and more & 0.437 & 0.496 & 0 & 1 \\
\hline Individual annual income & & & & \\
No employment income & 0.020 & 0.140 & 0 & 1 \\
Less than 20000 & 0.251 & 0.433 & 0 & 1 \\
20000-39999 & 0.256 & 0.436 & 0 & 1 \\
$40000-59999$ & 0.192 & 0.394 & 0 & 1 \\
$60000-79999$ & 0.117 & 0.321 & 0 & 1 \\
80000 and more & 0.163 & 0.369 & 0 & 1 \\
\hline
\end{tabular}

In Burkina Faso, cigarettes consumption is higher than Canada with almost six cigarettes consumed per day on average. More than two third of individuals in our sample have no less than a primary education. The sample is composed of $51 \%$ of women and almost $70 \%$ of them are married. All the thirteen regions are also represented in our sample. This diversity in our sample allow us to estimate the partial effects of each factor on the incidence of smoking, as measured by the number of cigarettes smoked per day by the individual.

Table 2. Descriptive statistics (Burkina Faso)

\begin{tabular}{lllll}
\hline Variables & Mean & Sd & Min & Max \\
\hline Number of cigarettes per day & 5.922 & 20.62 & 0 & 99 \\
\hline Age & & & 0 & 1 \\
$25-34$ & 0.235 & 0.424 & 0 & 1 \\
$35-44$ & 0.168 & 0.374 & 0 & 1 \\
$45-54$ & 0.128 & 0.334 & 0 & 1 \\
55 and more & 0.161 & 0.368 & & \\
\hline Sex & & & 0 & 1 \\
Female & 0.515 & 0.500 & 0 & 1 \\
\hline Education level & & & 0 & 1 \\
Primary & 0.215 & 0.411 & 0 & 1 \\
Secondary & 0.068 & 0.252 & & \\
Higher & 0.006 & 0.077 & 0 & 1 \\
\hline Marital status & & & 0 & 1 \\
Married & 0.696 & 0.460 & 0 & 1 \\
Widowed & 0.049 & 0.217 & 0 & 1 \\
Divorced & 0.012 & 0.111 & 0.092 &
\end{tabular}




\begin{tabular}{lllll}
\hline Region & & & & \\
Cascades & 0.066 & 0.249 & 0 & 1 \\
Center & 0.084 & 0.278 & 0 & 1 \\
East Center & 0.076 & 0.266 & 0 & 1 \\
North Center & 0.073 & 0.261 & 0 & 1 \\
West Center & 0.086 & 0.281 & 0 & 1 \\
South Center & 0.069 & 0.255 & 0 & 1 \\
East & 0.087 & 0.282 & 0 & 1 \\
Upper Bassins & 0.081 & 0.274 & 0 & 1 \\
North & 0.079 & 0.270 & 0 & 1 \\
Central plateau & 0.073 & 0.261 & 0 & 1 \\
Sahel & 0.069 & 0.255 & 0 & 1 \\
South West & 0.068 & 0.252 & 0 & 1 \\
\hline
\end{tabular}

\section{Econometric Model}

The aim of our paper is to estimate the impact of economic, socio-demographic and geographic factors on smoking practice as measured by the number of cigarettes smoked per day. Given the type of our dependent variable (count data), the Poisson model is best suited for this analysis. We control for regional fixed effects to account for regional differences in both countries.

Let $\mathrm{N}$ be the number of individuals, cigi the average number of cigarettes smoked by the individual per day, and Xi the vector of explanatory variables. Xi includes potential factors that may affect the number of cigarettes smoked including, gender, age, marital status, respondent's income, employment, respondent's level of education, respondent's household income, number of children under twelve (12) years of age in the respondent's household, and respondent's geographic location. The conditional mean of the Poisson model is written.

$$
\lambda_{i}=\exp \left(X^{\prime}{ }_{i} \beta\right)
$$

where $\beta$ represents the vector of parameters.

The likelihood function of the model is written:

$$
\operatorname{Pr}\left(C I G=\operatorname{cig}_{i} \mid X_{i}\right)=\frac{e^{-\lambda_{i}\left(X_{i}\right)} \lambda_{i}\left(X_{i}\right)^{c i g_{i}}}{\operatorname{cig}_{i} !}
$$

The estimators of $\beta$ are estimated by maximizing the log-likelihood function:

$$
\log L(\beta)=\frac{1}{N} \sum_{i=1}^{N} \log \left[\operatorname{Pr}\left(C I G=\operatorname{cig}_{i} \mid X_{i}\right)\right]
$$

To deal with the potential clustering of observations at the neighbourhood level, we estimate the multivariate model using heteroskedasticity robust standard errors. In order to conduct the interpretations, the marginal effect of each variable on cigarettes consumption are estimated.

\section{Empirical Results}

\subsection{Factors Affecting Tobacco Consumption in Canada}

The results of our estimation are reported in Table 3, while the marginal effects, which will be used for interpretations, are reported in Table 4.

In Model (i), we include only individual variables such as the individual's age group, sex, education, and income as explanatory variables for smoking status as measured by the number of cigarettes consumed per day. Our results show that age has a positive effect on the number of cigarettes consumed. However, this effect takes the form of an inverted $U$ with a peak observed at the 40-54 age group. Indeed, individuals aged 25-39 years smoke on average 1.46 cigarettes per day more than individuals under 25 years of age (see Table 4, Margin (i)). The consumption rises to 2.32 cigarettes for those aged $40-54$ before returning to 1.72 cigarettes for those over 55-64 years of age. It then drops to 0.25 for those over 64 years of age. Furthermore, the results suggest that men have a greater tendency 
to smoke than women, with about 1.45 more cigarettes consumed than women. In addition, our results suggest that education reduces the tendency to smoke. Compared to individuals with no high school education, individuals with high school education consume 1.79 fewer cigarettes per day. The consumption declines to 2.96 fewer cigarettes per day for individuals with post-secondary or university education. Wealth also have a negative effect on cigarette consumption from $\$ 40,000$ income upwards.

Model (ii) controls for marital status, household wealth, the number of children under 12 in the household and the employment status of the individual. The results show that age, being male, and being unmarried have a positive effect on cigarette consumption. Conversely, education, income and employment have a negative effect on cigarette consumption.

In model (iii), we control for province of residence fixed effects. Our results show that the impact of age on cigarette consumption retains an inverted U-shape. Compared to the model (ii), we observe that the effects of age groups are positive, significant, and stronger when we control for regions of residence. Peak consumption is observed at the 40-54 age group, which consumes about 2.38 cigarettes per day more than youth under 25 years of age. Men consume on average more than 1.34 cigarettes per day than women. Like the previous specifications, the results confirm that individual income has a negative effect on cigarette consumption after the $\$ 40,000$ per year cut-off. Married people consume fewer cigarettes than persons not formally married. The same result is observed for those who have a stable employment. Indeed, they consume on average 0.23 fewer cigarettes per day compared to the unemployed individuals. Having a child under the age of 12 is also an incentive to reduce the number of cigarettes consumed.

Table 3. Estimated coefficients (Canada)

\begin{tabular}{|c|c|c|c|}
\hline & Model (i) & Model (ii) & Model (iii) \\
\hline \multicolumn{4}{|l|}{ Age } \\
\hline \multirow[t]{2}{*}{$25-39$} & $0.70^{* * *}$ & $0.71^{* * *}$ & $0.71^{* * *}$ \\
\hline & $(0.04)$ & $(0.04)$ & $(0.04)$ \\
\hline \multirow[t]{2}{*}{$40-54$} & $0.96^{* * *}$ & $0.97 * * *$ & $0.99^{* * *}$ \\
\hline & $(0.04)$ & $(0.04)$ & $(0.04)$ \\
\hline \multirow[t]{2}{*}{$55-64$} & $0.79^{* * *}$ & $0.78^{* * *}$ & $0.80^{* * *}$ \\
\hline & $(0.04)$ & $(0.04)$ & $(0.04)$ \\
\hline \multirow[t]{2}{*}{65 and +} & $0.16^{* * *}$ & $0.14^{* *}$ & $0.17^{* * *}$ \\
\hline & $(0.04)$ & $(0.05)$ & $(0.05)$ \\
\hline \multicolumn{4}{|l|}{ Sexe } \\
\hline \multirow[t]{2}{*}{1 if male } & $0.53^{* * *}$ & $0.49^{* * *}$ & $0.49^{* * *}$ \\
\hline & $(0.02)$ & $(0.02)$ & $(0.02)$ \\
\hline \multicolumn{4}{|c|}{ Level of education } \\
\hline \multirow[t]{2}{*}{ Secondary } & $-0.44^{* * *}$ & $-0.34^{* * *}$ & $-0.32^{* * *}$ \\
\hline & $(0.02)$ & $(0.02)$ & $(0.02)$ \\
\hline \multirow[t]{2}{*}{ Higher } & $-0.90^{* * *}$ & $-0.78^{* * *}$ & $-0.75^{* * *}$ \\
\hline & $(0.02)$ & $(0.02)$ & $(0.02)$ \\
\hline \multicolumn{4}{|c|}{ Individual annual income } \\
\hline \multirow[t]{2}{*}{ Less than 20000} & $0.29^{* * *}$ & 0.05 & 0.05 \\
\hline & $(0.06)$ & $(0.06)$ & $(0.06)$ \\
\hline \multirow[t]{2}{*}{$20000-39999$} & 0.11 & 0.04 & 0.04 \\
\hline & $(0.06)$ & $(0.06)$ & $(0.06)$ \\
\hline \multirow[t]{2}{*}{$40000-59999$} & -0.12 & -0.03 & -0.03 \\
\hline & $(0.06)$ & $(0.07)$ & $(0.07)$ \\
\hline
\end{tabular}




\begin{tabular}{llll}
\hline $60000-79999$ & $-0.24^{* * *}$ & -0.06 & -0.06 \\
& $(0.07)$ & $(0.07)$ & $(0.07)$ \\
\hline 80000 and more & $-0.46^{* * *}$ & -0.14 & $-0.16^{*}$ \\
& $(0.07)$ & $(0.07)$ & $(0.07)$ \\
\hline
\end{tabular}

\begin{tabular}{|c|c|c|c|}
\hline \multicolumn{4}{|l|}{ Marital status } \\
\hline \multirow{2}{*}{\multicolumn{2}{|c|}{ Common-law union }} & $0.71^{* * *}$ & $0.72^{* * *}$ \\
\hline & & $(0.03)$ & $(0.03)$ \\
\hline \multirow{2}{*}{\multicolumn{2}{|c|}{ Widowed, divorced, separated }} & $0.65^{* * *}$ & $0.66^{* * *}$ \\
\hline & & $(0.03)$ & $(0.03)$ \\
\hline \multirow{2}{*}{\multicolumn{2}{|c|}{ Single }} & $0.55^{* * *}$ & $0.56^{* * *}$ \\
\hline & & $(0.03)$ & $(0.03)$ \\
\hline \multicolumn{4}{|l|}{ Household total income } \\
\hline \multirow[t]{2}{*}{ 20000-39999 } & & $-0.17^{* * *}$ & $-0.17^{* * *}$ \\
\hline & & $(0.03)$ & $(0.03)$ \\
\hline \multirow[t]{2}{*}{$40000-59999$} & & $-0.31^{* * *}$ & $-0.31^{* * *}$ \\
\hline & & $(0.04)$ & $(0.04)$ \\
\hline \multirow[t]{2}{*}{ 60000-79999 } & & $-0.40^{* * *}$ & $-0.40^{* * *}$ \\
\hline & & $(0.04)$ & $(0.04)$ \\
\hline \multirow[t]{2}{*}{80000 and +} & & $-0.57^{* * *}$ & $-0.58^{* * *}$ \\
\hline & & $(0.04)$ & $(0.04)$ \\
\hline \multirow[t]{2}{*}{ Have children under 12} & & $-0.06^{*}$ & $-0.08^{* *}$ \\
\hline & & $(0.03)$ & $(0.03)$ \\
\hline \multirow[t]{2}{*}{ Stable employment } & & $-0.09^{* * *}$ & $-0.09^{* * *}$ \\
\hline & & $(0.02)$ & $(0.02)$ \\
\hline Regional fixed-effects & NO & $\mathrm{NO}$ & YES \\
\hline \multirow[t]{2}{*}{ (Intercept) } & $0.68^{* * *}$ & $0.64 * * *$ & $0.70^{* * *}$ \\
\hline & $(0.07)$ & $(0.08)$ & $(0.09)$ \\
\hline Observations & 81862 & 81862 & 81862 \\
\hline Ajusted R-square & 0.83 & 0.89 & 0.91 \\
\hline
\end{tabular}

Standard errors in parentheses.

*** $\mathrm{p}<0.01, * * \mathrm{p}<0.05,{ }^{*} \mathrm{p}<0.1$

Table 4. Estimated marginal effects (Canada)

\begin{tabular}{llll}
\hline & Margin (i) & Margin (ii) & Margin (iii) \\
\hline Age & & & $1.474^{* * *}$ \\
$25-39$ & $1.457^{* * *}$ & $1.486^{* * *}$ & $2.382^{* * *}$ \\
$40-54$ & $2.324^{* * *}$ & $2.371^{* * *}$ & $1.724^{* * *}$ \\
$55-64$ & $1.719^{* * *}$ & $1.686^{* * *}$ & $0.268^{* * *}$ \\
65 and & $0.251^{* * *}$ & $0.219^{* *}$ & \\
\hline Sex & & & $1.342^{* * *}$ \\
1 if Male & $1.45^{* * *}$ & $1.351^{* * *}$ & $-1.23^{* * *}$ \\
\hline Education level & & & $-2.357^{* * *}$ \\
Secondary & $-1.787^{* * *}$ & $-1.326^{* * *}$ & $-2.466^{* * *}$ \\
Higher & $-2.966^{* * *}$ & & \\
\hline
\end{tabular}




\begin{tabular}{|c|c|c|c|}
\hline \multicolumn{4}{|l|}{ Individual annual income } \\
\hline Moins de $20000 \$$ & $0.929^{* * *}$ & 0.505 & 0.138 \\
\hline $20000 \$-39999 \$$ & 0.309 & 0.110 & 0.120 \\
\hline $40000 \$-59999 \$$ & -0.307 & -0.091 & -0.084 \\
\hline $80000 \$$ and + & $-1.002^{* * *}$ & -0.354 & $-0.399^{*}$ \\
\hline \multicolumn{4}{|l|}{ Marital status } \\
\hline Common-law union & & $1.87^{* * *}$ & $1.915^{* * *}$ \\
\hline Widowed, divorced, separated & & $1.67^{* * *}$ & $1.682^{* * *}$ \\
\hline Single & & $1.332^{* * *}$ & $1.352^{* * *}$ \\
\hline \multicolumn{4}{|l|}{ Household total income } \\
\hline $20000 \$-39999 \$$ & & $-0.580^{* * *}$ & $-0.593^{* * *}$ \\
\hline $40000 \$-59999 \$$ & & $-1.002^{* * *}$ & $-1.017^{* * *}$ \\
\hline $60000 \$-79999 \$$ & & $-1.245^{* * *}$ & $-1.250^{* * *}$ \\
\hline $80000 \$$ and + & & $-1.652^{* * *}$ & $-1.668^{* * *}$ \\
\hline Having children under 12 & & $-0.151^{*}$ & $-0.207^{* *}$ \\
\hline Stable employment & & $-0.261^{* * *}$ & $-0.236^{* * *}$ \\
\hline Regional fixed-effects & NO & $\mathrm{NO}$ & YES \\
\hline
\end{tabular}

Standard errors in parentheses.

$* * * \mathrm{p}<0.01, * * \mathrm{p}<0.05, * \mathrm{p}<0.1$

\subsection{Factors Affecting Tobacco Consumption in Burkina Faso}

We report the estimated coefficients of the Poisson model in Table 5, while the marginal effects are reported in Table 6 . The model (1) uses individual's age group, sex, education, and income as explanatory variables for the number of cigarettes consumed per day. The results indicate that age has a positive inverted U-shape effect on cigarette consumption. However, unlike Canada the younger group (25-34 years old) have the highest rate of cigarette consumption. Indeed, individuals aged 25-34 years smoke on average 1.71 cigarettes per day more than individuals under 25 years of age (see Table 6, Margin (1)). Furthermore, the results suggest cigarette consumption is higher for men. The gender gap in tobacco consumption between men and women is larger in Burkina Faso (5.021 cigarettes) compared to Canada (1.45 cigarettes). In addition, our results suggest that education reduces smoking. Compared to individuals with no education, individuals with primary education consume 0.16 fewer cigarettes per day. The consumption decreases to 0.89 cigarettes per day for individuals with secondary education and 0.81 for individuals with higher education.

In Model (2) we include marital status and wealth index as covariates. The results show that being married, divorced, or widowed reduced cigarettes consumption. For wealth index, we find that the poorer, middle, and richer groups tend to consume less cigarettes compared to the richest and the poorest individuals.

Finally, model (3) controls for province of residence fixed effects and the results remains consistent. 
Table 5. Estimated coefficients (Burkina Faso)

\begin{tabular}{|c|c|c|c|}
\hline VARIABLES & Model (1) & Model (2) & Model (3) \\
\hline \multicolumn{4}{|l|}{ Age } \\
\hline \multirow[t]{2}{*}[25-34]{} & $0.289 * * *$ & $0.526 * * *$ & $0.499 * * *$ \\
\hline & $(0.0123)$ & $(0.0154)$ & $(0.0154)$ \\
\hline \multirow[t]{2}{*}{ [35-44] } & $0.228 * * *$ & $0.551 * * *$ & $0.550 * * *$ \\
\hline & $(0.0133)$ & $(0.0183)$ & $(0.0183)$ \\
\hline \multirow[t]{2}{*}{ [45-54] } & $0.0936^{* * *}$ & $0.419 * * *$ & $0.438 * * *$ \\
\hline & $(0.0156)$ & $(0.0203)$ & $(0.0202)$ \\
\hline \multirow[t]{2}{*}{55 and more } & $-0.158 * * *$ & $0.191 * * *$ & $0.216^{* * *}$ \\
\hline & $(0.0267)$ & $(0.0297)$ & $(0.0297)$ \\
\hline \multicolumn{4}{|l|}{ Sex } \\
\hline \multirow[t]{2}{*}{1 if Male } & $0.513^{* * *}$ & $0.589^{* * *}$ & $0.592^{* * *}$ \\
\hline & $(0.012)$ & $(0.018)$ & $(0.021)$ \\
\hline \multicolumn{4}{|l|}{ Education level } \\
\hline \multirow[t]{2}{*}{ Primary } & $-0.0272 * *$ & $-0.184 * * *$ & $-0.191 * * *$ \\
\hline & $(0.0122)$ & $(0.0129)$ & $(0.0132)$ \\
\hline \multirow[t]{2}{*}{ Secondary } & $-0.150 * * *$ & $-0.486^{* * *}$ & $-0.460 * * *$ \\
\hline & $(0.0138)$ & $(0.0157)$ & $(0.0159)$ \\
\hline \multirow[t]{2}{*}{ Higher } & $-0.138 * * *$ & $-0.610 * * *$ & $-0.730 * * *$ \\
\hline & $(0.0327)$ & $(0.0341)$ & $(0.0343)$ \\
\hline \multicolumn{4}{|l|}{ Marital status } \\
\hline \multirow[t]{2}{*}{ Married } & & $-0.424 * * *$ & $-0.405 * * *$ \\
\hline & & $(0.0152)$ & $(0.0152)$ \\
\hline \multirow[t]{2}{*}{ Widowed } & & $-0.620 * * *$ & $-0.589 * * *$ \\
\hline & & $(0.0860)$ & $(0.0861)$ \\
\hline \multirow[t]{2}{*}{ Divorced } & & $-0.733 * * *$ & $-0.656 * * *$ \\
\hline & & $(0.0490)$ & $(0.0490)$ \\
\hline \multicolumn{4}{|l|}{ Wealth index } \\
\hline \multirow[t]{2}{*}{ Poorer } & & $-0.235^{* * *}$ & $-0.0926 * * *$ \\
\hline & & $(0.0163)$ & $(0.0166)$ \\
\hline \multirow[t]{2}{*}{ Midde } & & $-0.249 * * *$ & $-0.0993 * * *$ \\
\hline & & $(0.0165)$ & $(0.0172)$ \\
\hline \multirow[t]{2}{*}{ Richer } & & $-0.157 * * *$ & $-0.0407 * *$ \\
\hline & & $(0.0159)$ & $(0.0170)$ \\
\hline \multirow[t]{2}{*}{ Richest } & & $0.306^{* * *}$ & $0.292 * * *$ \\
\hline & & $(0.0155)$ & $(0.0173)$ \\
\hline Regional fixed-effects & $\mathrm{NO}$ & $\mathrm{NO}$ & YES \\
\hline \multirow[t]{2}{*}{ Constant } & $1.671 * * *$ & $1.849 * * *$ & $1.034 * * *$ \\
\hline & $(0.0103)$ & $(0.0139)$ & $(0.0275)$ \\
\hline Observations & 7,734 & 7,734 & 7,734 \\
\hline Ajusted R-square & 0.75 & 0.82 & 0.86 \\
\hline
\end{tabular}

Standard errors in parentheses.

$* * * \mathrm{p}<0.01, * * \mathrm{p}<0.05, * \mathrm{p}<0.1$. 
Table 6. Estimated marginal effects (Burkina Faso)

\begin{tabular}{lccc}
\hline VARIABLES & Margin (1) & Margin (2) & Margin (3) \\
\hline Age & $1.712^{* * *}$ & $3.117^{* * *}$ & $2.788^{* * *}$ \\
$25-34$ & $1.351^{* * *}$ & $3.264^{* * *}$ & $3.155^{* * *}$ \\
$35-44$ & $0.554^{* * *}$ & $2.480^{* * *}$ & $2.368^{* * *}$ \\
$45-54$ & $-0.938^{* * *}$ & $1.131^{* * *}$ & $1.039^{* * *}$ \\
55 and more & & & \\
\hline Sexe & $4.152^{* * *}$ & $4.851^{* * *}$ & $5.021^{* * *}$ \\
1 if Male & & & \\
\hline Education level & $-0.161^{* *}$ & $-1.090^{* * *}$ & $-1.183^{* * *}$ \\
Primary & $-0.891^{* * *}$ & $-2.880^{* * *}$ & $-2.514^{* * *}$ \\
Secondary & $-0.817^{* * *}$ & $-3.614^{* * *}$ & $-3.531^{* * *}$ \\
Higher & & & $-2.582^{* * *}$ \\
\hline Marital status & & $-2.509^{* * *}$ & $-3.451^{* * *}$ \\
Married & & $-3.674^{* * *}$ & $-3.731^{* * *}$ \\
Widowded & & $-4.339^{* * *}$ & \\
Divorced & & & $-0.498^{* * *}$ \\
\hline Wealth index & & $-1.394^{* * *}$ & $-0.532^{* * *}$ \\
Poorer & & $-1.472^{* * *}$ & $-0.224^{* * *}$ \\
Middle & & $-0.931^{* * *}$ & $1.910^{* * *}$ \\
Richer & & $1.815^{* * *}$ & NES \\
Richest & & 7,734 &
\end{tabular}

Standard errors in parentheses.

$* * * \mathrm{p}<0.01,{ }^{* *} \mathrm{p}<0.05,{ }^{*} \mathrm{p}<0.1$.

\section{Discussion and Conclusion}

This paper shed light on the factors affecting tobacco smoking, as measured by the number of cigarettes consumed per day in Burkina Faso and Canada. We use data from Burkina Faso 2016 Demographic and Health Survey and the 2015-2016 Canadian Community Health Survey (CCHS). We perform multivariate fixed effects regressions to estimate the partial effects of the individual, economic and social factors considered on the number of cigarettes smoked per day on average by the individual.

The results indicate that smoking is affected by a variety of individual and socioeconomic factors. First and foremost, our results point to the level of education as a major factor in tobacco consumption. This finding is consistent with similar studies such as Pierce et al. (1989); Giskes et al. (2005); Huisman et al. (2005) and Pampel et al. (2015) which show that the least educated people pay less attention to their health and the risks associated with tobacco, alcohol and drug use. At the second level, social and economic quality of life variables such as marriage, stable employment, parenthood of a child under 12, personal income, and household wealth are also determinants of cigarette consumption. These results are also in line with the literature which shows that people with an unstable family life and little responsibility are the most likely to switch to chronic smoking (Goffette, 2016; Cho et al., 2008). This finding therefore implies that policies to improve social living conditions and educational attainment should, in the long term, reduce the overall incidence of smoking in the population. Contrary to literature, which assumes that young people are the most affected by smoking (Brown and Rinelli, 2010; Reisi et al., 2014; Mohammadi et al., 2017), our results suggest that people over the age of 25, and more specifically, Generation X (40-55 years old), are the most affected by smoking in Canada. In contrast, in Burkina 
Faso, the result indicate that young people are the most affected by tobacco smoking. This result poses major public health and an economic development challenges giving the damaging effect of cigarette on health status.

In terms of policies implication, public actions aiming to educate and improve social conditions (family stability) should help reducing tobacco consumption in both countries. An interesting avenue for future research would be to extend the analysis to include alcohol and drug use, and also to take into account the tendency of individuals to underestimate their use of prohibited and/or socially stigmatized substances such as alcohol, tobacco and drugs in survey data. An approach based on the "Zero-Inflated Poisson Estimation" model could be implemented to correct for these measurement errors.

\section{Competing Interests Statement}

The authors declare that there are no competing or potential conflicts of interest.

\section{References}

Action on Smoking and Health, (2019). Fact sheet: Tobacco and the Developing World. July 2019

Bonnechère, B., Cissé, K., Millogo, T., Ouédraogo, G. H., Garanet, F., Ouedraogo, M. A., \& Kirakoya-Samadoulougou, F. (2019). Tobacco use and associated risk factors in Burkina Faso: results from a population-based cross-sectional survey. BMC public health, 19(1), 1466. https://doi.org/10.1186/s12889-019-7826-6

Brown, S. L., \& Rinelli, L. N. (2010). Family structure, family processes, and adolescent smoking and drinking. Journal of research on adolescence, 20(2), 259- 273. https://doi.org/10.1111/j.1532-7795.2010.00636.x

Cho, H. J., Khang, Y. H., Jun, H. J., \& Kawachi, I. (2008). Marital status and smoking in Korea: the influence of gender and age. Social science \& medicine, 66(3), 609-619. https://doi.org/10.1016/j.socscimed.2007.10.005

Giskes, K., Kunst, A. E., Benach, J., Borrell, C., Costa, G., Dahl, E., ... \& Lahelma, E. (2005). Trends in smoking behaviour between 1985 and 2000 in nine European countries by education. Journal of Epidemiology \& Community Health, 59(5), 395-401. https://doi.org/10.1136/jech.2004.025684

Goffette, C. (2016). Déterminants individuels et contextuels de la consommation de tabac. Revue française de sociologie, 57(2), 213-239. https://doi.org/10.3917/rfs.572.0213

Gritz, E. R., Nielsen, I. R., \& Brooks, L. A. (1996). Smoking cessation and gender: the influence of physiological, psychological, and behavioral factors. Journal of the American Medical Women's Association (1972), 51(1-2), $35-42$.

Hosseinpoor, A. R., Parker, L. A., d'Espaignet, E. T., \& Chatterji, S. (2011). Social determinants of smoking in low-and middle-income countries: results from the World Health Survey. PloS one, 6(5), e20331.

Huisman, M., Kunst, A. E., \& Mackenbach, J. P. (2005). Inequalities in the prevalence of smoking in the European Union: comparing education and income. Preventive medicine, 40(6), 756-764. https://doi.org/10.1016/j.ypmed.2004.09.022

Jetty, R., Banerji, A., Berry, M., Leigh, F. R., Goldade, R., Irvine, J., ... \& Morningstar, M. (2017). L'utilisation du tabac à des fins rituelles et le tabagisme chez les enfants et les adolescents autochtones du Canada. Paediatrics \& Child Health, 22(7), 400-405. https://doi.org/10.1093/pch/pxx122

Kelishadi, R., Moghtadaei, M., Khavarian, N., \& Famouri, F. (2007). Training parents or children? Which is more successful in controlling passive smoking?

McGinnis, J. M., \& Foege, W. H. (1993). Actual causes of death in the United States. Jama, 270(18), 2207-2212. https://doi.org/10.1001/jama.1993.03510180077038

Mohammadi, S., Ghajari, H., Valizade, R., Ghaderi, N., Yousefi, F., Taymoori, P., \& Nouri, B. (2017). Predictors of smoking among the secondary high school boy students based on the health belief model. International Journal of Preventive Medicine, 8. https://doi.org/10.4103/ijpvm.IJPVM_264_16

Ockene, I. S., \& Miller, N. H. (1997). Cigarette smoking, cardiovascular disease, and stroke: a statement for healthcare professionals from the American Heart Association. Circulation, 96(9), 3243-3247. https://doi.org/10.1161/01.CIR.96.9.3243

Pampel, F., Legleye, S., Goffette, C., Piontek, D., Kraus, L., \& Khlat, M. (2015). Cohort changes in educational disparities in smoking: France, Germany and the United States. Social Science \& Medicine, 127, 41-50. https://doi.org/10.1016/j.socscimed.2014.06.033 
Pierce, J. P., Fiore, M. C., Novotny, T. E., Hatziandreu, E. J., \& Davis, R. M. (1989). Trends in cigarette smoking in the United States: educational differences are increasing. Jama, 261(1), 56-60. https://doi.org/10.1001/jama.1989.03420010066034

Reisi, M., Javadzade, S. H., Shahnazi, H., Sharifirad, G., Charkazi, A., \& Moodi, M. (2014). Factors affecting cigarette smoking based on health-belief model structures in pre-university students in Isfahan, Iran. Journal of education and health promotion, 3. https://doi.org/10.4103/2277-9531.127614

Reitsma, M. B., Fullman, N., Ng, M., Salama, J. S., Abajobir, A., Abate, K. H., ... \& Adebiyi, A. O. (2017). Smoking prevalence and attributable disease burden in 195 countries and territories, 1990-2015: a systematic analysis from the Global Burden of Disease Study 2015. The Lancet, 389(10082), 1885-1906. https://doi.org/10.1016/S0140-6736(17)30819-X

Wald, N. J., \& Hackshaw, A. K. (1996). Cigarette smoking: an epidemiological overview. British medical bulletin, 52(1), 3-11. https://doi.org/10.1093/oxfordjournals.bmb.a011530

World Health Organization [WHO]. (2015). WHO global report on trends in prevalence of tobacco smoking 2015. Geneva: World Health Organization.

World Health Organization [WHO]. (2017). WHO report on the global tobacco epidemic, 2017: monitoring tobacco use and prevention policies. Geneva: World Health Organization.

\section{Copyrights}

Copyright for this article is retained by the author(s), with first publication rights granted to the journal.

This is an open-access article distributed under the terms and conditions of the Creative Commons Attribution license (http://creativecommons.org/licenses/by/4.0/). 